\title{
Why deservingness theory needs qualitative research: Comparing focus group discussions on social welfare in three welfare regimes
}

International Journal of Comparative Sociology

(C) The Author(s) 2019 Article reuse guidelines: sagepub.com/journals-permissions DOI: I0.1 I77/00207।5219837745 journals.sagepub.com/home/cos

\author{
Tijs Laenen \\ KU Leuven, Belgium
}

\section{Federica Rossetti}

KU Leuven, Belgium

\section{Wim van Oorschot}

KU Leuven, Belgium

\begin{abstract}
This article argues that the ever-growing research field of welfare deservingness is in need of qualitative research. Using focus group data collected in Denmark, Germany, and the United Kingdom, we show that citizens discussing matters of social welfare make explicit reference not only to the deservingness criteria of control, reciprocity, and need but also to a number of context-related criteria extending beyond the deservingness framework (e.g. equality/universalism). Furthermore, our findings suggest the existence of an institutional logic to welfare preferences, as the focus group participants to a large extent echoed the normative criteria that are most strongly embedded in the institutional structure of their country's welfare regime. Whereas financial need is the guiding criterion in the "liberal" United Kingdom, reciprocity is dominant in "corporatist-conservative" Germany. In "social-democratic" Denmark, it appears impossible to single out one dominant normative criterion. Instead, the Danish participants seem torn between the criteria of need, reciprocity, and equality/universalism.
\end{abstract}

\section{Keywords}

Denmark, Germany, qualitative research, United Kingdom, welfare deservingness, welfare regimes

\section{Introduction}

In the present-day Europe of permanent austerity, where the financial sustainability of the welfare state is continuously being scrutinized, the issue of how and to whom the ever-more scarce welfare

\section{Corresponding author:}

Tijs Laenen, Centre for Sociological Research, KU Leuven, Parkstraat 45, 3000 Leuven, Belgium. Email: tijs.laenen@kuleuven.be 
resources are allocated is again high on the political agenda. In such a context, in-depth knowledge of the normative criteria underpinning citizens' welfare distribution preferences is of crucial importance to all actors in the political arena. For obvious reasons concerning re-election and democratic legitimacy (Burstein, 2003; Pierson, 2001), office-seeking politicians, for example, have strong incentives to implement social policies and to voice political messages that are in tune with popular criteria. According to welfare deservingness theory, citizens use five criteria-the so-called "CARIN criteria"- to justify what constitutes a fair distribution of social welfare funds among various policy target groups: Control, Attitude, Reciprocity, Identity, and Need (van Oorschot et al., 2017). Considerable progress has been made in the ever-growing body of research contributing to our understanding of the relationship between popular deservingness opinions and welfare policy preferences. However, we argue that the further development of the research field is impeded by the relatively limited knowledge of its fundamentals: the CARIN criteria. Two issues to which qualitative research might offer a potential solution are of particular importance in this regard. The first is that the top-down character of the research process through which the CARIN criteria came into being - first deduced from existing literature and subsequently tested in survey researchmakes it difficult for us to claim with any certainty that people actually apply (all of) these five criteria or perhaps apply others. The second issue is that we do not really know the concrete meanings such abstract deservingness criteria have to people and how they apply such criteria.

In an attempt to scrutinize people's use of deservingness criteria more accurately, we adopt a qualitative approach to the study of welfare deservingness, in which we analyze data from 12 focus groups (FGs) in three different European countries: Denmark (DK), Germany (DE), and the United Kingdom (UK). The FG participants were invited to freely discuss and rank six different hypothetical vignettes (i.e. an unemployed person, a pensioner, an average-income family with children, a low-income worker, a relatively well-off worker, and an immigrant) in terms of their welfare deservingness. The open-ended structure of the FG discussions provides a fruitful opportunity to grasp which deservingness criteria people spontaneously articulate when justifying welfare preferences and what meaning is given to the different criteria. The cross-national design of our study has the additional advantage that it enables us to explore the frequently cited idea that deservingness considerations play out differently in different institutional settings, welfare regimes in particular (Laenen, 2018; Larsen, 2006; van Oorschot et al., 2017).

We find that in the three countries examined, the FG participants made explicit reference to the deservingness criteria of need, control, and reciprocity in a number of different ways, but not to attitude and identity. In addition, reference was made to three alternative criteria that are outside of the deservingness framework, because they refer more to broader society than to characteristics of welfare targets: equality/universalism, cost awareness, and social investment (the latter only in Denmark). In the following, we refer to these as "context-related criteria." Our analyses further show that the normative criteria used by selected groups of citizens discussing social welfare relate to the criteria embedded in their country's welfare regime (Clasen and van Oorschot, 2002; EspingAndersen, 1990). In liberal Britain, the need criterion dominates the discussions, whereas in corporatist-conservative Germany, it is clearly the reciprocity criterion. The FG participants in social-democratic Denmark mostly apply the criteria of universalism/equality, reciprocity, and need.

The remainder of the article is divided into four sections. The "Why welfare deservingness theory needs qualitative research" section elaborates on the welfare deservingness theory and argues that it needs qualitative research to develop further. In the "Research design" section, the FG data and analytical strategy is described in detail. The "Results" section depicts the deservingness discussions of the FGs in the selected countries and includes a cross-country comparison in which our findings are interpreted against general welfare state characteristics ("welfare regime" 
types) of the countries involved. Finally, we provide our conclusions and discuss some possible avenues for future research.

\section{Why welfare deservingness theory needs qualitative research}

The core claim of the welfare deservingness model, as depicted in Figure 1, is that public support for social benefits and services is to a large extent contingent on the perceived deservingness of their respective target groups (van Oorschot, 2000, 2006; van Oorschot et al., 2017). A target group's overall welfare deservingness, in turn, depends on how citizens evaluate that group on five crucial deservingness criteria and the importance they attach to such criteria when forming an opinion. The first of the CARIN criteria, control, refers to the idea that those perceived to have little or no personal control over getting into or out of their situation are judged to be more deserving of social welfare. The second, attitude, denotes the assumption that people seen as grateful and compliant are judged to be more deserving of social welfare. The third criterion, reciprocity, suggests that those perceived to have made higher contributions to society in the past, or who will do so in the present or future, are deemed to be more deserving of social welfare. The fourth criterion, identity, relates to people perceived as belonging to one's in-group being deemed more deserving of social welfare. The last criterion, need, refers to the idea that those perceived to have high financial or health needs are deemed to be more deserving of social welfare.

A rapidly growing body of research deals with attempts to empirically test deservingness theory (Buss, 2018; Jeene, 2015; Kallio and Kouvo, 2015; Kootstra, 2016; Laenen, 2018; Larsen, 2006; Petersen, 2012; van Oorschot, 2006; van Oorschot et al., 2017). To this end, most rely on quantitative techniques of data gathering and data analysis; regression analysis of survey data in particular. Two major analytical approaches have emerged in this survey-dominated research field (van Oorschot et al., 2017). The first involves measuring the CARIN criteria and their effects on policy preferences by using standard survey items that attempt to capture respondents' initial perceptions of target groups on the different deservingness dimensions. The second approach uses vignette experiments, in which respondents are asked to rate the welfare deservingness of hypothetical but specific claimants with different characteristics, all supposedly related to the CARIN criteria. Despite the progress being made, "several components are still underdeveloped or warrant further clarification" (van Oorschot et al., 2017: 350). We argue that two issues in particular impede the further development of welfare deservingness literature. Both are the result of the top-down character of previous research, to which more bottom-up qualitative research might offer a solution.

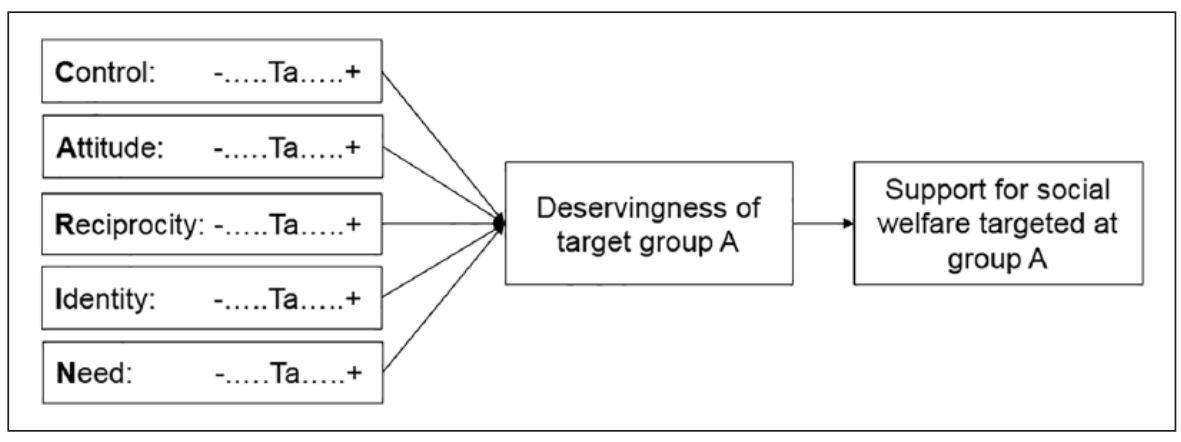

Figure I. The current basic welfare deservingness model.

Ta: position target group A on "negative-positive" dimension of a deservingness criterion. 
The first and perhaps most fundamental issue is that on the basis of earlier work on welfare deservingness, we cannot say with any certainty that ordinary people actually apply the five - and only those five- deservingness criteria identified in the CARIN model. The current deservingness framework is the result of a deductive process in which researchers first derived from existing literature (e.g. Cook, 1979; De Swaan, 1988) which criteria people may find important when deciding who should get what from the welfare state (van Oorschot, 2000, 2006). Later research uses predefined survey items or vignette experiments with fixed-response options to assess how the criteria are related to welfare distribution preferences (van Oorschot et al., 2017). However, in doing so, researchers are in danger of blindly assuming that what people think closely corresponds with what academics believe people think. On the basis of such top-down survey research alone, it remains difficult to tell which criteria citizens actually apply when forming opinions about welfare distribution. It is possible, for example, that not all five CARIN criteria are (equally) important to people or that criteria not yet recognized in deservingness literature also play a role in opinion formation.

The second major issue is that we know relatively little about the concrete meanings that abstract deservingness criteria have to people. To date, survey researchers have made use of expert knowledge to translate the CARIN criteria into specific items or vignette attributes. However, once again, expert knowledge might differ from popular perception. It is possible that certain items or attributes that, according to researchers, fall under the heading of a particular deservingness criterion are interpreted otherwise by the public. The number of children in the household of a benefit recipient, for example, is typically considered to be an indication of need in the eyes of deservingness experts but could equally be understood by people as a sign of reduced personal control over finding a job, as having (young) children might hamper the recipient from looking for work. Deservingness researchers also face the problem that certain items or attributes may relate to multiple deservingness criteria because they might mean very different things to different people (van Oorschot et al., 2017). For example, suppose that a vignette describes a recipient who has an additional income besides a welfare benefit. Individual A might perceive this information as an indication of less neediness (need), but individual B could interpret having an extra income as fraudulent behavior and thus as a sign of ungratefulness to society (attitude), and individual $\mathrm{C}$ might even welcome the fact that the recipient is working and contributing at least something to society (reciprocity).

According to van Oorschot and Roosma (2015: 25), what the deservingness framework needs in order to tackle these issues is "qualitative research, e.g. in the form of in depth interviewing or forum groups, in which people are asked to freely discuss and reveal what kind of criteria they are inclined to apply to specific needy groups," as this kind of research "could be very helpful in discovering which attributes of target groups indicate particular deservingness criteria and whether current deservingness research is overlooking particular criteria used by the public" (van Oorschot et al., 2017: 350). Unlike survey-based research with predefined items and fixed-response options, the open-ended questions asked in qualitative research offer much more room for spontaneous reactions on the part of respondents (Taylor-Gooby and Leruth, 2018). As a result, in-depth interviews or FGs should provide fertile ground to grasp which deservingness criteria people actually apply when deciding who should get what from the welfare state, how these criteria are applied, and what they really mean to people. However, to our knowledge, only two previously published studies approach the issue of welfare deservingness from a qualitative perspective. Both Kremer (2016) and Osipovič (2015) analyzed the attitudes of labor migrants residing in the Netherlands and the United Kingdom, respectively, toward the welfare entitlements of newly arrived immigrants. Both studies show a strong and persistent preference for making access to social welfare conditional on past contributions in terms of work and payment of (payroll) taxes. In practice, this entails excluding newly arriving migrants from welfare, at least for some time, because they are perceived to have contributed little to the host society. When discussing the social rights of 
migrants, notions of reciprocity thus appear to outweigh other deservingness considerations such as need or identity. In the current article, we extend the relatively narrow scope of previous qualitative work by studying how citizens living in different countries feel about welfare distribution with regard to a much broader range of target groups: the unemployed, the elderly, families with children, low-income workers, well-off workers, and immigrants.

\section{Research design}

In order to study people's social welfare preferences and their use of deservingness criteria, we analyzed data from 12 FGs conducted in autumn 2016 in three European countries (Denmark, Germany, and the United Kingdom, each representing a specific "welfare regime" type), as part of the cross-national research project "Welfare State Futures: Our Children's Europe" (WelfSOC). A FG design was preferred over other qualitative (e.g. in-depth interviews) or quantitative (e.g. experimental surveys) techniques, because it enhances interpersonal discussions and thus creates unique opportunities to investigate the normative criteria underlying the arguments raised in such discussions (Goerres and Prinzen, 2012). Because full cross-country standardization was not considered feasible or desirable, the WelfSOC project allowed for national adaptations in line with country-specific particularities (e.g. asking about student benefits in Denmark, but not in Germany or the United Kingdom). The general selection procedure and structure of the FGs, however, were similar across the three countries. The FG participants were recruited by national agencies with the help of specific guidelines provided by the WelfSOC coordination team and were given a small reimbursement to encourage participation. In each country, four relatively homogeneous groups consisting of about five to ten participants were formed on the basis of a number of socio-demographic characteristics that are known to be relevant for understanding popular welfare attitudes (e.g. age, gender, and income): a middle-class group, a working-class group, a group of elderly people, and a group of young people (see Appendix 1 for more details). In Germany and the United Kingdom, the FGs were organized and conducted by the commercial agencies of Ipsos Germany and Breaking Blue Research, respectively. In Denmark, this was done by researchers from the Center for Comparative Welfare Studies of Aalborg University. However, due to the close supervision of the WelfSOC coordination team, the choice between a commercial and an academic organization is unlikely to have had a substantial impact on our results.

The FGs were structured along three stages. The first was a warm-up exercise, in which the moderator encouraged the participants to brainstorm about what comes to mind when thinking of "the welfare state." Second, six vignettes, representing different policy target group representatives, were presented to the participants: an unemployed person, a pensioner, a family with children on an average income, a low-income worker, a relatively well-off worker, and an immigrant. Participants were asked what types of benefits and services these people should get from the welfare state, and why they thought that ought to be the case. The vignettes were deliberately described very broadly, to gauge what type of information (e.g. age, health, and behavior) participants would need in order to make judgments about the vignettes. After discussing each case separately, in the last stage, participants were asked to rank the six vignettes in terms of their welfare deservingness. A potentially important difference between the countries is that in Germany the vignettes were given specific names (e.g. the immigrant was called "Adrian"), and participants were individually instructed to rank them, and only discussed their rankings in a group setting afterward. In the United Kingdom and Denmark, the vignettes were instead described in general terms (e.g. "an immigrant") and the task was to come up with a ranking based on group consensus. This might have made things more "personal" in the German FGs and could have enhanced participants' identification with and generosity toward the vignettes. See Appendix 2 for some examples of how the 
FG topic, the vignettes, and the ranking exercise were introduced in the different countries and Appendix 3 for a summary table of the final group rankings.

All 2-hour FG sessions were audio recorded and the recordings were transcribed in full. The German and Danish transcripts were translated into English to ease cross-national comparison. Using NVivo 11 software, we examined the FG transcripts by means of a directed content analysis; a qualitative approach that starts from existing theory or previous research to identify key concepts as initial codes (Hsieh and Shannon, 2006). This particular coding approach seemed most appropriate for the study, because as discussed in the theoretical section, there is already a relatively large body of literature concerning the normative deservingness criteria people apply when making distributive decisions (Saldaña, 2009). Five predefined codes were derived from the theoretical perspective of welfare deservingness: control, attitude, reciprocity, identity, and need. In addition to the a priori coding scheme, ample room was left for the bottom-up recognition of arguments that could not be categorized under one of the five predefined codes but were nevertheless used as justifications for granting or withholding welfare entitlements. As shown in the "Results" section, this led to the identification of three additional codes that we group under the heading of "contextrelated criteria": equality/universalism, cost awareness, and social investment (the last only in Denmark). These context-related criteria are different from the deservingness criteria, in that they do not pertain to the characteristics of welfare targets (e.g. their neediness or contributions) but refer instead to broader society and its welfare system.

The coding process followed three steps. First, each researcher independently coded the texts according to the theoretically defined principles, while also leaving room for other codes to emerge. In this way, we left open the possibility to assign multiple codes to a single quote. Second, the reliability of the codes was discussed among the researchers. A code was accepted if, and only if, at least two out of three members of the research team were in agreement. In an attempt to limit researchers' bias in interpreting the FG transcripts as much as possible, we coded only those statements given by respondents in which the following three core elements were recognized: (i) a personal claim of fairness on (ii) the topic of entitlement to social welfare benefits and/or services (e.g. pensions, healthcare, and childcare), for which (iii) the person gave a justification as to why the welfare entitlement should or should not be granted. Personal opinions about the fair distribution of other benefits and burdens - such as wages, taxes, or work obligations - were excluded from the analysis, as were factual statements that referred to the actual state of affairs instead of the ideal situation people had in mind. We report here an example of a statement made by a respondent that was coded as "reciprocity":

I think (i) personal claim it's terrible that someone who's worked for 30 years (iii) justification related to reciprocity only gets one or two years of unemployment money, (ii) welfare entitlement whereas a Hartz IV person [a person who receives unemployment assistance; Arbeitslosengeld II] gets what they get. This goes more deeply into it, but I think it's unfair if everyone gets what they get unconditionally rather than having something to do with earning it. (DE-MC-8)

\section{Results}

\section{United Kingdom}

In the British FGs, discussions were dominated by the criterion of need. There was widespread, sometimes tacit, agreement among the participants that welfare resources ought to be allocated according to individual-mainly financial — need. When presented with the vignettes representing different target groups, the British respondents first and foremost considered questions such as: How 
needy is this person? How much money is coming in and how much money is going out? What is the household income or salary? Does that income stem from a single earner or from multiple earners? What costs and expenses do people have? How much are they paying in rent and energy bills? How many dependents (e.g. children and elderly relatives) are reliant on the income? On the basis of such a fine-grained financial assessment, in which incoming revenue is weighed against outgoing expenditure, it is decided which welfare benefits and services ought to be awarded; with the simple rule of thumb being that higher needs should give rise to higher levels of social protection. For example, when asked about the relevance of age in distributing benefits and services, one respondent replied,

Yes I think the age does matter. There are some young people that live by themselves and it doesn't really matter about age, but if they are living at home why would they need more money if their mum and dad are paying for the rent and they only have to pay for, say, their bus travel or the new clothes that they want, when an older person would be having to worry about bills and rent and council tax or whatever accommodation they are in? (UK-YO-4)

The preponderance of the need criterion in the UK discussions manifested itself even more strongly in the ranking exercise that the participants were asked to perform. Although the rank orders the FGs ultimately decided on were quite divergent, the process leading to the preferred ranking was quite similar across the groups, with need being the guiding principle in all of them. If there was any discussion at all in the British FGs, it was primarily about the issue of who needs the benefits most. Thus, although the preferred distributional norm was shared across almost all participants, the perceptions concerning concrete need differed quite strongly between participants. For example, whereas some considered the elderly to be a target group facing particularly high needs, others maintained that they are relatively well-off: "They have probably got a pension. They are as "sound as a pound.' Don't worry about them!" (UK-YO-1). The following response to the moderator's inquiry about why the immigrant was put in a particular position in the rank order exemplifies the ranking reasoning of most British participants: "We need more information but they [immigrants] need the help. They are in that place because the people above probably need it more and the people below don't need it" (UK-WC-1).

Means testing proved to be very popular among the FG participants_-for example, "I think everything should be means tested" (UK-YO-7) and "Means testing is good" (UK-MC-5) — and it was mentioned in relation to a broad range of benefits and services: childcare, pensions, unemployment benefits, tax credits, and so on. Quite frequently, participants mentioned that citizens with incomes above a certain, yet often undefined, upper threshold should not be granted rights to (some) welfare entitlements, as “there has to be a cut-off at some point, doesn't there?" (UK-WC1). On the contrary, some of the participants claimed that due to the exponential growth in the cost of living, people on higher incomes should nonetheless be included in the scope of the welfare state. In addition to financial need, health needs were - albeit far less frequently - also cited as arguments in favor of granting welfare entitlements. More specifically, health needs were mentioned with regard to delivering benefits and services to the elderly (old-age care and pensions) and the sick/disabled (disability benefits and mental health services).

In addition to the need criterion, two other deservingness criteria were referred to, although considerably less frequently and less decisively: control and reciprocity. The criterion of control was alluded to in three different ways. First and foremost, individual control over being unemployed or employed part-time was considered important for either granting or withholding welfare entitlements: "If they are able to work full time and they choose to work part time, I think they should be penalized. I don't think they should get help" (UK-WC-3) and "I think asylum seekers are not allowed to work, so then they have to be getting more money just to survive because they 
are not allowed to go and get any income" (UK-YO-10). Although most discussions revolved around the personal responsibility for being out of work, individual control over health was also mentioned as a reason for withholding certain benefits and services from people who make poor lifestyle choices, such as unhealthy eating and drug abuse. For example, when asked whether health makes a difference in terms of the benefits and services unemployed people should be entitled to, one of the respondents replied,

I am going to be really controversial but it depends on why they are not in good health. If I felt for example there was somebody who had cancer or it was an illness they couldn't control then fine, but I have a next door neighbor who takes drugs and who is not in good health. I would have an issue with that. (UK-MC-9)

A third way in which reference was made to the control criterion was by linking it to children. Children were generally regarded as innocent third party (Houtman, 1997; van Oorschot et al., 2017), from whom society should not take away any welfare benefits and services because of the choices made by their parents, as "it is not really fair to punish the children for what the parents decide to do, or don't do" (UK-MC-3). Because of its close connection to the issue of personal responsibility, we did not assign a separate code to this type of reasoning.

The criterion of reciprocity was primarily referred to as past contributions instead of future contributions, and served as an argument for either granting or withholding social welfare entitlements. On one hand, past or present contributions were mentioned as reasons why different target groupssuch as the elderly, low-income workers, and well-off workers - who have been putting money into the welfare pot by working and paying taxes should be granted benefits and services. For example, while ranking the different vignettes, one respondent noted that "the 70 year old has worked for a good part of their life and they deserve something back" (UK-WC-1). On the other hand, immigrants were denied access to social rights because people felt they had not yet contributed enough to British society. If migrants work and contribute to society, however, most respondents felt they should also be entitled to the same welfare benefits and services: "My son lives in New Zealand and they have lots of different countries but they [immigrants] are not entitled to anything until they have worked and proved themselves. I don't think that is a bad thing" (UK-OL-4).

Leaving room for a bottom-up recognition of justifications that could not be allocated to one of the five CARIN criteria led to the identification of two alternative context-related criteria. These extend beyond the deservingness framework because they do not refer to characteristics of welfare targets but to broader society. The first context-related criterion, equality/universalism, was typically discussed in terms of equal access to (not equal levels of) welfare services (not benefits); healthcare in particular. Most participants agreed that access to the National Health Service (NHS) should be universal and free for all, because healthcare is considered to be a basic human need. However, it should be remembered that this consensus was broken by the few respondents who felt that healthcare treatment should depend on personal responsibility for ill health. Equality was also mentioned as an argument for granting welfare entitlements to immigrants, who, according to some participants, should be treated equally in terms of benefits and services because it is a human right. For example, when asked what immigrants should be entitled to, a respondent replied,

Healthcare $100 \%$ and I don't care if someone has come from a different country and they have got a heart problem, and it doesn't matter if they are paying into our system. I think it's a basic human right to have healthcare and they should definitely get access and no checks and nothing given to them. (UK-YO-6)

During the ranking exercise, some participants also expressed a basic attitude toward equality, which states that everyone should get the same, mostly high-level, welfare benefits and services: 
"Everybody is equal to access whatever" (UK-MC-9). Such expressions of all-embracing unconditionality were relatively rare, though. A second, albeit marginal, context-related criterion we encountered in the FG data was that of cost awareness, which was referred to in two main ways. First, it was used as a reason for excluding immigrants from welfare benefits and services, the NHS in particular:

We would all like to help everybody but at the moment it just can't be done. We haven't got the facilities. We haven't got anything here, have we? We just seem to be taking money out that we just haven't got and ruining the National Health Service, which should never be ruined. (UK-OL-4)

In addition to the financial feasibility of the welfare state, cost awareness was also mentioned as an argument in favor of means testing, and thus, de facto, in favor of distribution according to financial need. Because people think public resources are scarce, they feel that the welfare state apparatus has to make sure that those resources are geared toward people who need them the most. Here, one might recognize the main trait for which means testing is extensively praised in social policy literature (van Oorschot, 2002): its ability to institutionalize a cost-efficient distribution of welfare between society's rich and poor. However, some of the respondents also pointed to one of the most cited arguments against means testing: its high administrative cost. Nevertheless, as this was commonly cited as a mere side-note, the policy instrument of means testing remained relatively popular among the FG participants.

\section{Germany}

The discussions in the German FGs were dominated by the criterion of reciprocity. A recurring idea among the participants was that an individual has to benefit from the welfare state based on what he or she has paid (or pays) into it. When the moderator presented the different vignettes with target group representatives, a frequent response among the German participants was to seek answers to the questions: How much has this person contributed to the system? For how long? How long has this person worked? Is he or she still working? The general idea is that welfare resources, particularly cash benefits, should be allocated according to the contributions paid in the past: those who have paid more deserve to receive more compared with those who have contributed for a shorter period, or not at all. For example,

If we talk about long-term unemployment, it depends on what he paid into the system, regardless of need, that's what he should get out of it, and that's OK. If I work and pay in more, then I want to have that back. (DE-WC-4)

The emphasis on work is central to these statements. The condition for being entitled to social welfare is that the person has worked for a certain period of time. The reciprocity criterion was not only used to justify the granting of social benefits but also to exclude those who have not contributed enough to the system. This was often the case for the immigrant vignette, who was not considered entitled to receive the same benefits as a German citizen 'because he hasn't paid anything into the country and his parents haven't paid anything [...]. Therefore he's not given anything to the state" (DE-WC-7). Only after a certain amount of years spent working in the country were immigrants considered as being entitled to receive welfare benefits. Although the biggest concern was past reciprocity, the idea of future reciprocity was also present among the German respondents. The state should invest in education and further training to give individuals the opportunity to find better jobs, thus allowing them to pay more into the welfare system. 
Investments are thus not seen as something that society as a whole can benefit from, but more as personal investments. Future reciprocity plays a particular role with regard to the family, lowincome workers, and the unemployed. For example, the purpose of supporting low-income workers can be seen in the following statement: "So that he gets better education/training and can get a better job, better earnings, and can then better pay into the public funds. That's the order of it in my view" (DE-OL-5).

Two other deservingness criteria, need and control, emerged about equally in the German debates. Need was mostly used as an argument to exclude from social welfare those who are able to cope using their own resources. Need is thus mainly conceived as financial need, with almost no reference to health needs in the German FGs. Although most of the time participants did not explicitly mention which type of support the wealthier should be excluded from, some participants suggested that nursery schools in particular should be based on income: "It's unfair, they have so much money, so why should they get everything for free?" (DE-OL-3). This use of the need criterion is more visible in the ranking exercise, in which the well-off worker was placed among the lowest positions by all four FGs: "He's doing well, so there's no need" (DE-YO-4); "[He] can take care of himself and provide for his own needs" (DE-MC-3). In some cases, however, need was also used to justify the granting of welfare entitlements, as those who have not paid enough in the past nevertheless cannot be left alone in poverty:

I'm talking about this idea of getting out what I paid into the system. That's going to vary, because one person who is 22 hasn't paid much of anything into the system, and if he is unemployed, should he go hungry or beg on the street? (DE-WC-10)

The control criterion was used as justification both for granting and for withholding welfare entitlements, with particular reference made to the individual responsibility to find a job. If a person is unemployed for reasons beyond his or her control, they are considered as being entitled to welfare support, and vice versa. In this regard, age and health were the two major factors mentioned as reasons why an individual should or should not receive social welfare. For example, referring to age, some argued that an unemployed person should be granted welfare entitlements "because he's 45 and could possibly have difficulty finding a new job depending on his situation" (DE-MC-5), while the low-income worker should not be the focus of the welfare state "because he's still young maybe and still has a number of possibilities that could play a role later on" (DEMC-8). With regard to health, a person is considered deserving of social welfare in case of disability, because a physical condition may prevent people from working, and thus providing for themselves: "If he's ill, then he should receive help. If there's a 55 year old woman who has problems with her whole body, then you can't expect her to work. You have to support her" (DEYO-8). By contrast, being in good health was used as a justification for withholding welfare entitlements, as reported with reference to the unemployed: "because if someone is physically in a position to work and there is work they can do, then I'm of the opinion they should go to work" (DE-MC-6).

The German participants also applied context-related criteria reaching beyond welfare deservingness. In the German groups, there was little reference to equal access to healthcare service, but equality was more related to some specific benefits, such as pensions. As opposed to the idea that welfare benefits should be based on contributions made in the past, some participants (particularly in the elderly FG) argued for equal pension levels:

"I'm in favor of a uniform or equal pension amount where everyone gets the same amount, like everyone gets 1500 euros. That's OK" (DE-OL-7). "Right, that's a good idea. I'd sign up immediately" (DE-OL-8). 
Equality/universalism was also used as argument for guaranteeing equality of access to the welfare state for immigrants, although without reference to which specific benefits or services: "If he is allowed to live here in Germany, then he's entitled to the same rights as everyone else here" (DE-YO-10). Finally, we identified the criterion of cost awareness, which was mainly interpreted as a concern about the fiscal sustainability of the welfare state and the ability of the state to maintain the system when resources are limited. In particular, participants referred to a fear related to immigration in Germany: "Too many people [are] coming here, and we can't possibly support them all adequately" (DE-YO-4). Some of the participants expressed a deep concern about the impossibility, for immigrants, to receive adequate support from the welfare state, due to the limited resources.

\section{Denmark}

In the Danish FG discussions, there was no single normative criterion that stood out as being most dominant. Instead, it seems that the Danish participants were torn between the criteria of need, reciprocity, and equality/universalism. This struggle between different criteria may be exemplified by what we call the "AP Møller debate." Danish respondents often spontaneously discussed whether AP Møller, the now deceased founder of the largest Danish multinational enterprise (Maersk) and archetypical representative of the well-off upper class in Denmark, ought to be entitled to social welfare. A lot of Danish participants argued that rich people should be excluded from receiving welfare benefits, child allowances, and pensions in particular, because they do not have a need for it:

I don't think that it makes sense for us to give a small state pension to some of the richest people in Denmark. That is, if they have all these millions at the bottom of the savings trunk, then I would think that they couldn't care less about what they get. (DK-YO-1)

However, as a counterargument, some participants claimed that it is unfair to exclude the wealthy, either because they have paid (often proportionally high) taxes and therefore deserve something back from the welfare state (reciprocity) or simply because they are residents/citizens of Denmark and should therefore be entitled to all welfare rights (equality/universalism). For example, when asked whether rich people should be granted a retirement pension, one of the respondents claimed that they should not because they are not needy, but another respondent disagreed, because he felt they have paid high taxes and should not be discriminated against:

I think it should be considered. I know what people say. We all served this country and so forth, but I still think from each according to his ability to each according to his need. (DK-OL-7)

I can completely understand your argument about having a high income, but at the same time, as you say [points to another participant], people pay taxes their entire lives and you still pay high taxes when you have a high income, even once you've retired. They pay lots of money. So I can completely understand, when you say, we can get rid of them. But you can't just do that. (DK-OL-6)

Also, when asked to rank the different vignettes, the Danish participants applied the three different rationales of need, reciprocity, and equality/universalism, instead of following one guiding principle. Despite the explicit instructions of the researchers to rank the vignettes in terms of their welfare deservingness, many Danish respondents initially refused to do so, as "in a welfare state, everybody deserves to get help" (DK-WC-4), and thus, "it is very un-welfare-state-like to rank 
them like this" (DK-YO-3). After further prompting and discussion, two competing rank order justifications emerged. Some suggested that the ranking should perhaps be based on what one has contributed to society. However, most Danish respondents felt uneasy about the idea of distributing welfare resources in proportion to past contributions, and ultimately decided to rank according to the need criterion. The struggle between these two deservingness criteria is exemplified by a respondent's reaction to the statement that the vignettes "should be ranked according to who has contributed the most" (DK-MC-5): "The whole point of a welfare state is that you don't have to deserve something, because you have contributed. You should deserve something because you need it" (DK-MC-1).

With regard to the need criterion, the Danish participants seemed to share a basic belief that no resident of Denmark ought to be poor, and therefore all sorts of welfare benefits (e.g. housing benefits, pensions, and social assistance) should be provided in order to prevent poverty. As having children in particular was considered to be very expensive by most, it was deemed necessary for families with children to receive support from the welfare state. Single parents, whose financial resources are perceived to be low, were in particular considered as being entitled to more favorable welfare entitlements, such as cheaper childcare and higher rates of child allowances. This is reflected in the common desire among the Danish participants to grade child benefits according to claimants' household income: the higher the income, the lower the benefit. Some participants also argued that rich people ought to be excluded altogether from child allowances and, albeit to a lesser extent, pensions. In practice, cutting off people whose earnings exceed a certain maximum level would imply the implementation of a means test. However, the Danish respondents hardly ever explicitly recommended means testing as being a suitable policy instrument. In addition to financial needs, adverse health was mentioned as a reason why (mostly older) people ought to be entitled to care services:

I think that something like home help, we shouldn't be slack with this. I think one should take it pretty seriously if people have something, often physical, which means that they cannot manage certain thingseither domestic chores or in regard to taking care of themselves - then I really think that they must get support with that. (DK-WC-4)

In the Danish discussions, the criterion of control revolved mainly around personal responsibility for being unemployed, but was mostly used as an argument for granting instead of withholding welfare benefits and services. Out of a basic belief that people are truly willing to work but are often not able to because of scarce job opportunities or bad health, most Danish respondents opted for the second of two scenarios described by one of the respondents:

I feel like there are two scenarios. One of them is that he [the unemployed vignette] wants to be unemployed and doesn't feel like working, in which case I still think he should be entitled to benefit, but that it should be low and he should be activated into looking for work just as happens today. If he is not unemployed through choice, then I think that he should be supported and be entitled to a higher rate of benefit than those, for example, who don't feel like working. (DK-WC-3)

The criterion of reciprocity was primarily used as a justification for distributing welfare resources to pensioners (for having worked for many years) and to well-off citizens (for having paid large amounts of taxes). Depending on the timing of contributions, reciprocity was also used to either grant welfare entitlements to immigrants or to withhold them from this group. If judgments were made on the basis of past contributions to Danish society, the general tendency was to deny immigrants access to benefits and services. When the focus shifted instead to potential contributions in 
the future, immigrants were considered to be much more deserving of social welfare. Such considerations of past and future reciprocity are exemplified in the following statement:

I find it hard to see how someone from Poland has earned anything for the Danish society. [...] I think you have to earn something before you can benefit from it. Or at least benefit and then earn. [...] I think that immigrants should also get something out of the welfare state, because that person will come to benefit later on, which is why it is also fair enough that such a person gets student benefits, because that person will most likely remain in Denmark and thus work and pay taxes here. So I think it should be like that. (DK-YO-5)

Closely linked to, but somewhat different from the criterion of future reciprocity, is the contextrelated criterion of social investment. Although both follow a return-on-investment reasoning, the reciprocity argument is about granting benefits and services to people because they, as individuals, are anticipated to pay back society in terms of tax contributions. The social investment argument involves the allocation of welfare resources so that people can become fully participating citizens, which in the long run will benefit society as a whole. To achieve the much-desired goal of a better society, spending on education and training (for all, but for unemployed and lower-educated people in particular), and child-related benefits and services was strongly promoted.

I think that society will be making a huge mistake if it seriously starts setting limits on higher education. We talk constantly about getting better qualified because it is so hard to find a qualified workforce and all that. I think that precisely here it would be a really good investment for society to reach, if it was necessary in some cases, and give two extra student grants or whatever was needed for people to advance towards the dream they have and get a higher education. (DK-WC-5)

The criterion of equality/universalism was reflected in the widespread agreement that access to welfare services - healthcare, nursery care, and education in particular - should be equal and universal, as these services are "part of the package when you live in Denmark" (DK-WC-1). The following statement, which was endorsed by most respondents in the FG, points to the tacit agreement that the universality of such welfare services is perhaps even non-negotiable:

When you [refers the moderator] say service, we haven't at any point talked about equal access and free access to hospitals and doctors. Because it's implicit. That's not what's meant in any of the questions, right? (DK-OL-3)

Furthermore, equality/universalism was used as an argument to justify why the rich should also be included in the Danish welfare system and why immigrants ought to have the right to welfare benefits and services:

It's not OK to treat people differently, I think. If we have a person who has come to our country, who we call an immigrant and who doesn't have a job, then they should have the same possibility to receive financial help, and that is missing, I think. (DK-OL-4)

The Danish participants also applied the context-related criterion of cost awareness, which appeared in two different forms. First, some respondents justified welfare retrenchment (e.g. of retirement pensions or dental care) out of a belief that the welfare state project is increasingly becoming unaffordable. Second, cost awareness served as an argument against means testing, as the administrative costs necessary to operate the means test was estimated to be higher than the potential gains. 


\section{Cross-national comparisons}

In this section, we briefly discuss some of the most striking cross-country differences and similarities (see Table 1 for a summary). The first common trend is that the FG participants made explicit references to the deservingness criteria of control, reciprocity, and need, but not to the criteria of attitude and identity. The control criterion was used primarily with reference to work status: those who were considered personally responsible for being jobless were granted less generous welfare provision compared with those perceived to be victims of circumstance. Only in the United Kingdom, control was also related to health status: some of the British participants felt that the welfare state should give less to those with unhealthy lifestyles. The reciprocity criterion was conceived in two ways: first, as contributions made in the past, and second, as contributions to be made in the future. Past reciprocity featured more frequently than future reciprocity, however, especially in the United Kingdom, where the future aspect was largely overlooked. The criterion of need was first and foremost interpreted as financial, but also as health needs, except in Germany, where the latter was seldom alluded to.

A second cross-national similarity is that the FG participants applied a number of alternative context-related criteria alongside the deservingness criteria; most notably the criterion of universalism/equality. In Denmark and the United Kingdom, the majority of participants argued for universal and equal access to welfare services, healthcare in particular. In Germany, however, equal old-age pensions seemed to be the main concern for some, especially in the elderly FG. The cost awareness criterion was used in a fairly similar fashion across the three countries, but only played a marginal role in each of them. The only notable country-specific deviation in this regard is that the German participants did not discuss the administrative cost of means testing, whereas the British and the Danish did. The social investment criterion, which refers to the provision of social welfare to individuals because that will benefit society as a whole, was unique to the Danish debates.

The most striking cross-country difference relates to the relative importance of the various normative criteria. In the United Kingdom, financial need stands out as the most frequently used and most decisive normative criterion behind popular welfare preferences. In Germany, it is

Table I. The relative importance of the normative criteria in the different welfare regimes.

\begin{tabular}{llll}
\hline & United Kingdom & Germany & Denmark \\
\hline Deservingness criteria & & & ++ \\
Control & ++ & ++ & 0 \\
Attitude & 0 & 0 & ++ \\
Reciprocity & + & +++ & ++ \\
$\quad$ Past & + & +++ & + \\
$\quad$ Future & 0 & ++ & 0 \\
Identity & 0 & 0 & ++ \\
Need & +++ & ++ & ++ \\
$\quad$ Financial & +++ & ++ & + \\
$\quad$ Health & + & 0 & +++ \\
Context-related criteria & & & + \\
Equality/universalism & ++ & ++ & + \\
Cost awareness & + & + & + \\
Social investment & 0 & 0 & \\
\hline
\end{tabular}

$0=$ not important; $+++=$ most important. 
clearly the criterion of (past) reciprocity. Only for Denmark is it difficult to single out one criterion as the most dominant. Instead, the Danish discussions encompass a mix of the criteria of need, reciprocity, and equality/universalism. These results can be interpreted in light of EspingAndersen's (1990) welfare regime typology (see also Clasen and van Oorschot, 2002), which since its inception three decades ago has been highly influential in comparative welfare state research. The typology identified three qualitatively different welfare state ideal-types as a critique to the then prevailing dominant way of understanding welfare state variation as differences in degree of social spending or "welfare effort" (see, for example, Wilensky, 1975). In EspingAndersen's view, the "liberal" regime type (present mostly in Anglophone countries, as, for example, the United Kingdom) is characterized by a focus on means-tested welfare provision, based on liberal conceptions of limited state influence and citizen's personal responsibilities. In this conception, the state mostly takes responsibility for people in poverty only. The "corporatist-conservative" regime type (typical for continental European countries, as, for example, Germany) is characterized by a focus on collective, contributory social insurances (with wageand contribution-related benefits) to provide for a range of social risks of (male) workers, whether poor or not. Responsibility for their welfare is shared between state and social partners (notably employers' organizations and trade unions). The "social-democratic" regime type (typical for Scandinavian countries as, for example, Denmark) provides a broad range of (mainly tax-financed) social benefits and social services for citizens generally (i.e. not mostly only for the poor or workers), with the objective of universally guaranteeing an equally high standard of living and well-being for all. In social-democratic Scandinavia, equality is thus a guiding principle in welfare rationing.

Against this background, in our view, the dominance of the need criterion in the UK FG discussions might reflect the relatively strong reliance on means-tested social assistance benefits found in the Anglophone liberal world of welfare. Likewise, the dominance of the "past reciprocity" criterion in Germany might epitomize the insurance-based character of corporativeconservative regimes, in which workers pay social contributions to insure themselves against possible future risks. The typical expectation that the criterion of equality/universalism is most strongly embedded - and thus supported - in the Scandinavian, social-democratic world of welfare, however, is not fully supported by the data. One possible explanation is that the policy emphasis on universalism has declined considerably in Denmark over recent decades (Béland et al., 2014; Clasen and van Oorschot, 2002). The Danish pension system, for one, is much less universal today than it was in the 1980s, when Esping-Andersen (1990) constructed his regime typology (Kangas et al., 2010), while more generally in Denmark, the scope of need-based assistance and reciprocity-based insurance has grown over the years (Clasen and van Oorschot, 2002). Conversely, in Germany and the United Kingdom, the predominance of the respective criteria of reciprocity and need has largely been preserved in the institutional design of welfare provision, with the exception mainly of the German unemployment benefit system, which has become more means-tested after the Hartz IV reforms (Clasen, 2011; Clasen and van Oorschot, 2002).

Even though the Danish reluctance to rank the different vignettes may be interpreted as an indirect, albeit rather weak, expression of a Nordic "passion for equality," most Danish participants routinely discriminated on the basis of individual need, contributions, and responsibility. Thus, there seems little evidence for the claim that deservingness discussions are more or less irrelevant in the Scandinavian systems of "Rolls-Royce universalism" (Larsen, 2006; Rothstein, 1998). It must be noted, however, that the Danish participants primarily applied the deservingness criteria to justify why benefits and services should be granted, instead of why they should be denied. This finding seems to suggest that the Danish participants, more than their UK and German 
counterparts, have an overall inclusionary perspective on social rights and take them for granted. This is in line with previous survey research suggesting that popular welfare attitudes, and deservingness opinions in particular, are generally more positive in Denmark than they are in Germany and the United Kingdom (Larsen, 2006). Overall therefore, there does seem to be - as Larsen (2006) suggests - some kind of "institutional logic" to popular welfare attitudes (see also TaylorGooby et al., 2018). Normative institutionalists, on one hand, would argue that this is because citizens learn, through lifelong socialization, to adapt their normative beliefs to the norms entrenched in the institutions (i.e. welfare regimes) they live under (Arts and Gelissen, 2001; Mau, 2003; Rothstein, 1998). On the other hand, popular beliefs could also be a driving force behind welfare state development, especially in democracies where political actors have strong electoral incentives to take the wishes of the general public into consideration (Brooks and Manza, 2006; Page and Shapiro, 1983). A more likely scenario therefore, is one of continuous covariation, in which public policy and public opinion constantly reinforce one another (Weissberg, 1976).

\section{Conclusions and discussion}

In this article, we have identified two major gaps in the welfare deservingness framework that are thought to impede its further development. The first is that the deductive nature of prior research in the deservingness field makes it difficult to tell to what extent people actually apply the five deservingness criteria that scholars have derived from existing literature. Perhaps people only use some of the "CARIN criteria" (van Oorschot et al., 2017), or apply other criteria that are not yet recognized in deservingness literature. The second gap is that we know relatively little about what concrete meaning these abstract criteria of deservingness have to people. What substance do people give to the criteria when deciding who should get what from the welfare state? Qualitative research, in which citizens are invited to freely discuss and motivate their deservingness opinions, offers a way forward in addressing these gaps. This could enhance our understanding of people's use of deservingness criteria, and ultimately, of the relationship between deservingness and public support for social welfare. To that purpose, we analyzed data from FGs conducted in three different welfare regimes - Denmark, Germany, and the United Kingdom - in which the participants discussed and ranked six different vignettes in terms of their welfare deservingness. Our main conclusion resulting from these analyses is fourfold.

First, when openly discussing matters of welfare distribution with their peers, the FG participants made explicit reference to the deservingness criteria of control, reciprocity, and need, but not to the criteria of attitude and identity. This is somewhat surprising, given that previous quantitative studies suggest that the deservingness dimensions of attitude (Laenen and Meuleman, 2018) and identity (Kootstra, 2016) are important determinants of popular welfare preferences. Therefore, we would advise caution with regard to prematurely concluding that attitude and identity simply do not matter when welfare deservingness is being judged. As for identity, it could be that the degree of openness inherent to the FG design yields a particular social desirability bias that prevents participants from articulating arguments concerning identity considerations. The attitude criterion, instead, might suffer from the problem of entailing everything and nothing at the same time. On one hand, attitude is "everything," because it is an all-encompassing concept covering a myriad of different types of law-abiding and norm-conforming behavior (gratitude, docility, compliance, honesty, pleasantness, etc.). On the other hand, attitude is also "nothing," because its broadness implies that it is less distinct from the other deservingness criteria. On a more general level, one could thus argue that attitude and identity are criteria that under certain conditions may tacitly shape welfare preferences, and they might surface more easily in the context of survey-based studies, for which social desirability bias is less of a problem than in FGs. We leave it up to future 
research to explore when (and why) deservingness criteria are used explicitly, and when (and why) they operate tacitly.

Second, our analyses provide deeper insight into the specific substance people give to the different deservingness criteria, and are therefore particularly informative for scholars who want to improve the operationalization of those criteria in future survey research. Despite its weaknesses, survey methodology still has plenty of strengths, such as the generalizability to broader populations, and remains highly relevant for studying welfare deservingness. With regard to the criterion of reciprocity, a distinction can be made between two different interpretations. On one hand, reciprocity was thought of by FG participants as contributions made in the past. On the other hand, reciprocity was often understood as potential contributions in the future. This distinction between past and future reciprocity is particularly relevant for the category of immigrants, whose perceived deservingness is dependent on the time perspective of choice. People who conceived reciprocity as past contributions were more likely to suggest excluding immigrants from the welfare system, but those who stressed the future aspect of reciprocity seemed more inclined to grant them access because of the potential contributions they were expected to make as tax-paying workers. Thus, when studying popular attitudes toward immigrants' welfare deservingness in survey research, for example, it seems crucial to take both types of reciprocity into account as explanatory factors. In a similar vein, need was interpreted in two distinct ways. First and foremost, the FG participants discussed the financial needs of the vignettes in terms of revenue (e.g. household income) and expenditure (e.g. rent). Although far less frequent, need was at the same time also interpreted as pertaining to the health needs of the vignettes. However, health needs might possibly have played a more prominent role if we had included a disability vignette, which was unfortunately not available in the chosen list (however, see Gollust and Lynch, 2011; Jensen and Petersen, 2017; van Der Aa et al., 2018). The control criterion was mainly framed as the personal responsibility people have over their work status (i.e. are you to blame for being unemployed?), but was also - at least in the United Kingdom — related to health status (i.e. are you to blame for being in bad health?).

Third, we found that the FG participants also applied three alternative normative criteria: equality/universalism, cost awareness, and social investment. What sets these "context-related" criteria apart from the deservingness framework is that they are not related to the characteristics of welfare targets (i.e. their needs, contributions, and personal responsibility), but to characteristics of the broader welfare system or even of society in general. The criterion of equality/universalism refers to the practice of making benefits and services unconditional and equal for all, and was mostly mentioned in relation to healthcare. Cost awareness arguments reflect concerns about matters such as the affordability of the welfare state and the administrative cost of means testing. The social investment argument, found only in Denmark, denotes the idea that the welfare state should invest in people through benefits and services so that society as a whole will thrive. It is important to note that the social investment perspective is different from what we term "future reciprocity," as the latter concerns giving social welfare to people on the condition that they, as individuals, pay back that support at a later point in time through work and (payroll) taxes.

Fourth, our analyses suggest the existence of - to put it in the words of Larsen (2006) - an "institutional logic" to welfare preferences. In discussing issues of fair welfare distribution, the British, Danish, and German FG participants appeared to echo the normative criteria that are most strongly embedded in the institutional structure of their respective welfare regimes (Clasen and van Oorschot, 2002; Esping-Andersen, 1990). In the liberal United Kingdom, there was widespread, sometimes tacit, agreement among the FG participants that welfare resources ought to be allocated according to individual, mainly financial, need. In corporatist-conservative Germany, with its emphasis on contributory social insurances, reciprocity stood out as the preferred distributive rule among the FG participants. Based on the idea that people should get out what they have paid into 
the social security system, the distribution of welfare resources was considered fair if it was more or less proportional to the amount of contributions people had made in the past, or alternatively, were expected to make in the future. In social-democratic Denmark, it proved impossible to single out one dominant normative criterion guiding the discussions. Instead, the Danish participants seemed torn between the criteria of need, reciprocity, and equality/universalism. It must be noted, however, that our analyses definitely do not constitute a hard test of the regime argument, as we did not study representative cross-sections of the population. Instead, our more-modest contribution is to show how the normative criteria used by a selected group of citizens discussing welfare distribution relate to the criteria embedded in the welfare regimes they live under.

Our results also relate to the broader and ongoing scholarly debate about the relative importance of different deservingness criteria. Previous quantitative studies comparing the relative weight of the CARIN criteria often singled out one particular criterion as the most important, but they tend to point in different directions (van Oorschot and Roosma, 2015). While most pinpoint personal control as being the most crucial deservingness dimension (Appelbaum, 2001; van Oorschot, 2000; Will, 1993), some suggest it to be attitude (Laenen and Meuleman, 2018), reciprocity (Mau, 2003; Petersen, 2012), identity (Gilens, 1999; Reeskens and van der Meer, 2018), or need (Groskind, 1991, 1994). Our findings bring more nuance to the debate, by suggesting that the importance attached to deservingness criteria depends to some extent on the institutional regime context in which a person lives (see also Larsen, 2006). Thus, when deciding who should get what from the welfare state, it not only matters who is judging (e.g. liberals or conservatives; Jeene et al., 2013) and who or what is being judged (e.g. unemployment benefits or healthcare; Jensen and Petersen, 2017), but also when and where the judgments are made (e.g. liberal, conservative, or universal welfare regimes; Larsen, 2006). Future studies should explore the context sensitivity of deservingness criteria further, by scrutinizing in greater detail how they are linked to country-specific policy trajectories (Uunk and van Oorschot, 2017), meso-level welfare schemes instead of macro-level welfare regimes (Laenen, 2018), and to alternative contextual factors such as the state of the economy (Jeene et al., 2014).

\section{Acknowledgements}

We are grateful to NORFACE for generating the data which this paper analyses as part of the WelfSOC project led by Peter Taylor-Gooby. We are also grateful to Nadja Doerflinger, the four anonymous reviewers and the editor for their constructive feedback on earlier drafts of this article.

\section{Declaration of conflicting interests}

The author(s) declared no potential conflicts of interest with respect to the research, authorship, and/or publication of this article.

\section{Funding}

The author(s) disclosed receipt of the following financial support for the research, authorship and/or publication of this article: This research was funded by FWO Vlaanderen (Grant Number: G076915 and G068816N) and NORFACE (Grant Number: 462-14-050).”

\section{ORCID iD}

Tijs Laenen (iD https://orcid.org/0000-0002-4705-196X

\section{References}

Appelbaum L (2001) The influence of perceived deservingness on policy decisions regarding aid to the poor. Political Psychology 22(3): 419-442. 
Arts W and Gelissen J (2001) Welfare states, solidarity and justice principles: Does the type really matter? Acta Sociologica 44(4): 283-299.

Béland D, Blomqvist P, Andersen JG, et al. (2014) The universal decline of universality? Social policy change in Canada, Denmark, Sweden and the UK. Social Policy and Administration 48(7): 739-756.

Brooks C and Manza J (2006) Social policy responsiveness in developed democracies. American Sociological Review 71(3): 474-494.

Burstein P (2003) The impact of public opinion on public policy: A review and an agenda. Political Research Quarterly 56(1): 29-40.

Buss C (2018) Public opinion towards targeted labour market policies: A vignette study on the perceived deservingness of the unemployed. Journal of European Social Policy. Epub ahead of print 15 March. DOI: $10.1177 / 0958928718757684$.

Clasen J and van Oorschot W (2002) Changing principles in European social security. European Journal of Social Security 4(2): 89-115.

Clasen J (ed.) (2011) Converging Worlds of Welfare? British and German Social Policy in the 21st Century. Oxford: Oxford University Press.

Cook F (1979) Who Should Be Helped? Public Support for Social Services. Beverly Hills, CA: SAGE.

De Swaan A (1988) In Care of the State: Healthcare, Education and Welfare in Europe and the USA in the Modern Era. Cambridge: Polity Press.

Esping-Andersen G (1990) Three Worlds of Welfare Capitalism. Cambridge: Polity Press.

Gilens M (1999) Why Americans Hate Welfare: Race, Media and the Politics of Anti-poverty Policy. Chicago, IL: The University of Chicago Press.

Goerres A and Prinzen K (2012) Can we improve the measurement of attitudes towards the welfare state? A constructive critique of survey instruments with evidence from focus groups. Social Indicators Research 109(3): 515-534.

Gollust SE and Lynch J (2011) Who deserves health care? The effects of causal attributions and group cues on public attitudes about responsibility for health care costs. Journal of Health Politics, Policy and Law 36(6): 1061-1095.

Groskind F (1991) Public reactions to poor families: Characteristics that influence attitudes toward assistance. Social Work 36(5): 446-453.

Groskind F (1994) Ideological influences on public support for assistance to poor families. Social Work 39(1): $81-89$.

Houtman D (1997) Welfare state, unemployment, and social justice: Judgments on the rights and obligations of the unemployed. Social Justice Research 10(3): 267-288.

Hsieh HF and Shannon SE (2006) Three approaches to qualitative content analysis. Qualitative Health Research 15(9): 1277-1288.

Jeene M (2015) Who Should Get What and Why, Under Which Conditions? Descriptions and Explanations of Public Deservingness Opinions. Ridderkerk: Ridderprint.

Jeene M, van Oorschot W and Uunk W (2013) Popular criteria for the welfare deservingness of disability pensioners: The influence of structural and cultural factors. Social Indicators Research 110(3): 1103-1117.

Jeene M, van Oorschot W and Uunk W (2014) The dynamics of welfare opinions in changing economic, institutional and political contexts: An empirical analysis of Dutch deservingness opinions, 1975-2006. Social Indicators Research 115(2): 731-749.

Jensen C and Petersen MB (2017) The deservingness heuristic and the politics of health care. American Journal of Political Science 61(1): 68-83.

Kallio J and Kouvo A (2015) Street-level bureaucrats' and the general public's deservingness perceptions of social assistance recipients in Finland. Social Policy and Administration 49(3): 316-334.

Kangas O, Lundberg U and Ploug N (2010) Three routes to pension reform: Politics and institutions in reforming pensions in Denmark, Finland and Sweden. Social Policy and Administration 44(3): 265-284.

Kootstra A (2016) Deserving and undeserving welfare claimants in Britain and the Netherlands: Examining the role of ethnicity and migration status using a vignette experiment. European Sociological Review 32(3): 325-328. 
Kremer M (2016) Earned citizenship: Labour migrants' views on the welfare state. Journal of Social Policy 45(3): 395-415.

Laenen T (2018) Do institutions matter? The interplay between income benefit design, popular perceptions, and the social legitimacy of targeted welfare. Journal of European Social Policy 28(1): 4-17.

Laenen T and Meuleman B (2018) Public support for the social rights and social obligations of the unemployed: Two sides of the same coin? International Journal of Social Welfare. Epub ahead of print 12 December 2018. DOI: 10.1111/ijsw.12369.

Larsen CA (2006) The Institutional Logic of Welfare Attitudes: How Welfare Regimes Influence Public Support. Aldershot: Ashgate Publishing Ltd.

Mau S (2003) The Moral Economy of Welfare States: Britain and Germany Compared. London: Routledge.

Osipovič D (2015) Conceptualisations of welfare deservingness by Polish migrants in the UK. Journal of Social Policy 44(4): 729-746.

Page B and Shapiro R (1983) Effects of public opinion on policy. The American Political Science Review 77(1): 175-190.

Petersen MB (2012) Social welfare as small-scale help: Evolutionary psychology and the deservingness heuristic. American Journal of Political Science 56(1): 1-16.

Pierson P (ed.) (2001) The New Politics of the Welfare State. Oxford: Open University Press.

Reeskens T and van der Meer T (2018) The inevitable deservingness gap: A study into the insurmountable immigrant penalty in perceived welfare deservingness. Journal of European Social Policy. Epub ahead of print 31 may 2018. DOI: 10.1177/0958928718768335

Rothstein B (1998) Just Institutions Matter: The Moral and Political Logic of the Universal Welfare State. Cambridge: Cambridge University Press.

Saldaña J (2009) The Coding Manual for Qualitative Researchers. London: SAGE.

Taylor-Gooby P, Hvinden B, Mau S, et al. (2018) Moral economies of the welfare state: A qualitative comparative study. Acta Sociologica. Epub ahead of print 13 June 2018. DOI: 10.1177/0001699318774835.

Taylor-Gooby P and Leruth B (eds) (2018) Attitudes, Aspirations and Welfare. Social Policy Directions in Uncertain Times. Basingstoke: Palgrave MacMillan.

Uunk W and van Oorschot W (2017) How welfare reforms influence public opinion regarding welfare deservingness: Evidence from Dutch time-series data, 1975-2006. In: van Oorschot W, Roosma F, Meuleman B, et al. (eds) The Social Legitimacy of Targeted Welfare. Attitudes to Welfare Deservingness. Cheltenham: Edward Elgar Publishing, pp.149-166.

van der Aa MJ, Paulus ATG, Hiligsmann MJC, et al. (2018) Varying opinions on who deserves collectively financed health care services: A discrete choice experiment on allocation preferences of the general public. The Journal of Health Care 55: 1-11.

van Oorschot W (2000) Who should get what, and why? On deservingness criteria and the conditionality of solidarity among the public. Policy and Politics 28(1): 33-48.

van Oorschot W (2002) Targeting welfare on the functions and dysfunctions of means-testing in social policy. In: Townsend P and Gordon D (eds) World Poverty: New Policies to Defeat an Old Enemy. Bristol: The Policy Press, pp. 171-193.

van Oorschot W (2006) Making the difference in social Europe: Deservingness perceptions among citizens of European welfare states. Journal of European Social Policy 16(1): 23-42.

van Oorschot W and Roosma F (2015) The Social Legitimacy of Differently Targeted Benefits, ImPRovE Working Paper No. 15/11. Antwerp: Herman Deleeck Centre for Social Policy-University of Antwerp.

van Oorschot W, Roosma F, Meuleman B, et al. (eds) (2017) The Social Legitimacy of Targeted Welfare: Attitudes to Welfare Deservingness. Cheltenham: Edward Elgar Publishing.

Weissberg R (1976) Public Opinion and Popular Government. Upper Saddle River, NJ: Prentice Hall.

Wilensky H (1975) The Welfare State and Equality: Structural and Ideological Roots of Public Expenditure. Berkeley, CA: University of California Press.

Will JA (1993) The dimensions of poverty: Public perceptions of the deserving poor. Social Science Research 22(3): 312-332. 


\section{Appendix I}

\section{Recruitment and selection of the focus group participants}

In each country, four relatively homogeneous groups consisting of about five to 10 participants were formed using the following recruitment guidelines:

Middle class: Completed higher education (i.e. 3 years or more), an income level equivalent to 150 percent of national median wage for a full-time worker over 25 , homeownership for the majority of the participants, maximum two students or unemployed, variation in their marital status (e.g. married/partner, single parent, parent with primary school children, parent with teenage children, empty nest parents, persons without children, etc.).

Working class: Less than 3 years higher education, the presence of at least four persons in the group without higher education, household income level below the third decile (e.g. under $£ 348$ weekly for United Kingdom), maximum two students or unemployed and variation in marital status.

Old age pensioners: Age 62-75 years (with majority age 67+), variation in pension benefit level (with at least two persons on lowest pension level/minimum pension), sufficient hearing as a condition for participation, some participants from single person households (widow, divorced, etc.) and some childless participants or with children who live far away.

Young adults: Age 18-35 (with the ideal aim to achieve an as even age distribution as possible), three students, at least three parents and with some variation in family status.

Furthermore, some common criteria for all groups were agreed upon: a gender balance, exclusion of politicians and persons working as market analysts; a balance between left- and right-wing participants; and inclusion of members of ethnic minorities. Table 2 reports for each country separately the list of participants from all FGs with their main socio-demographic characteristics. Unfortunately, there was an unexpectedly large amount of cancelations and non-show-ups in Denmark, which is why most of the Danish focus groups only had five participants. 


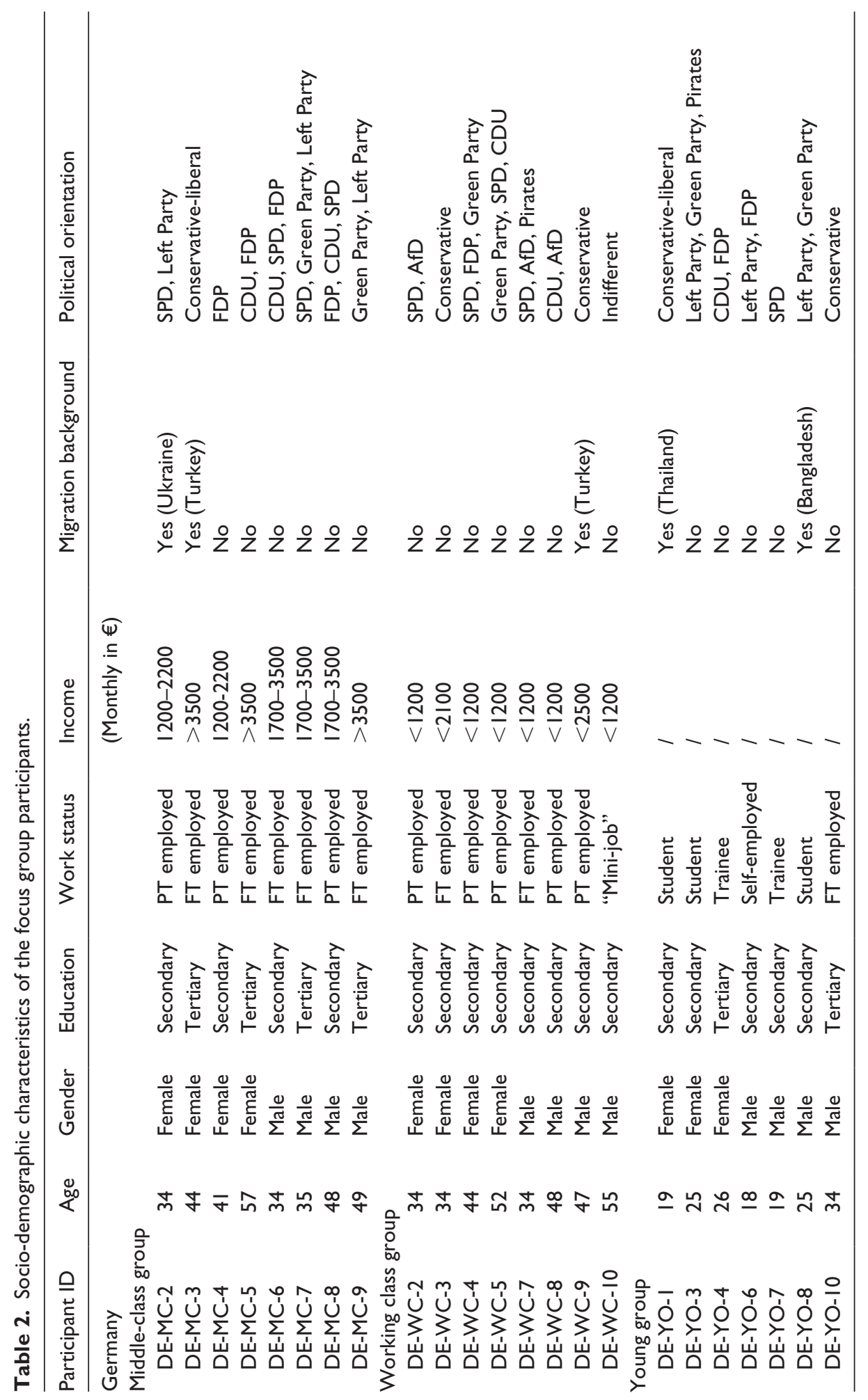




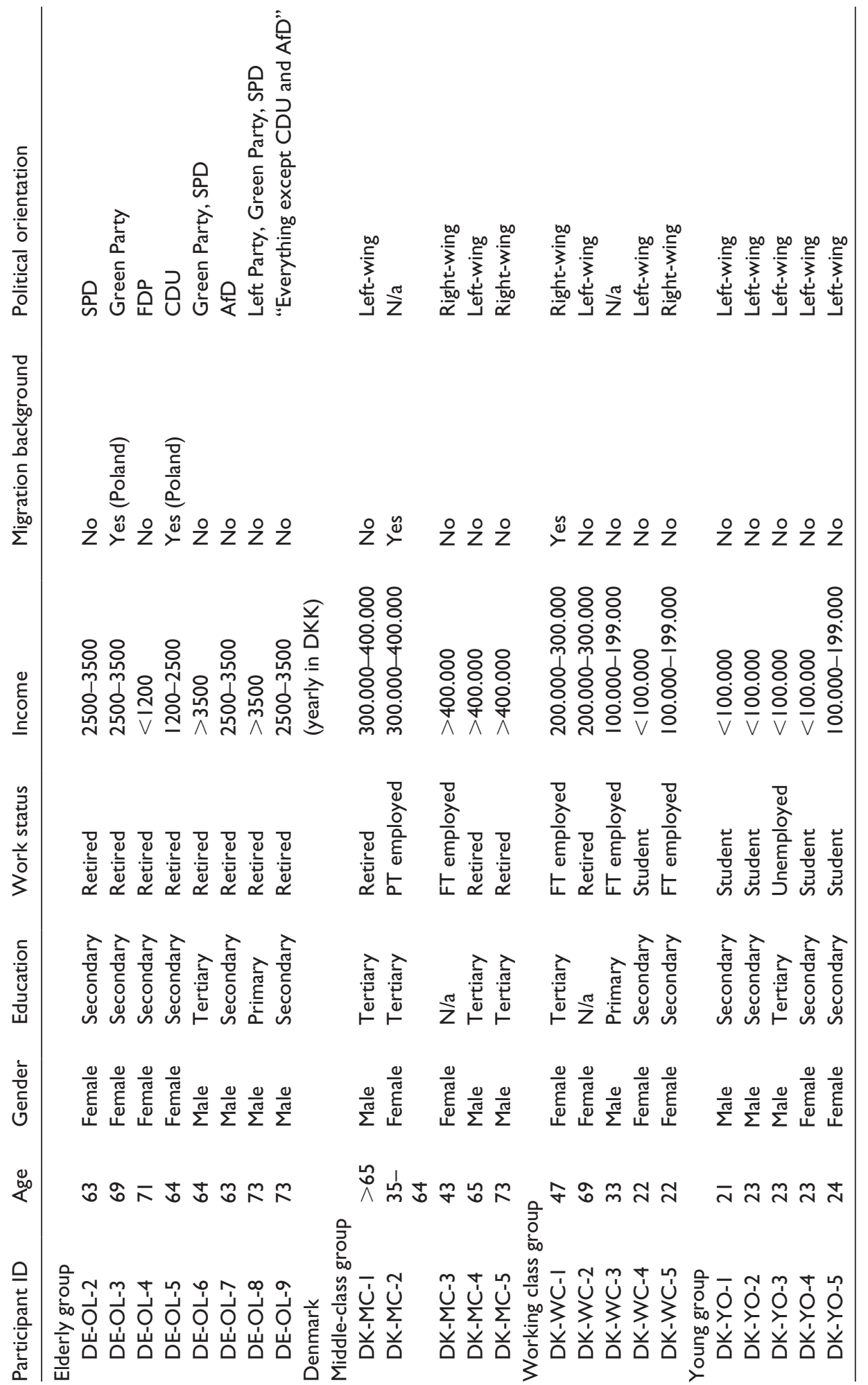




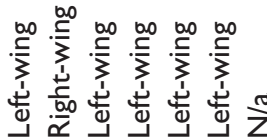

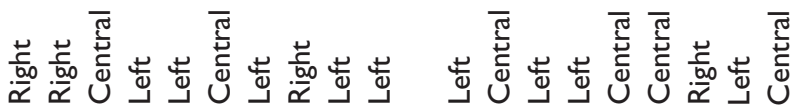

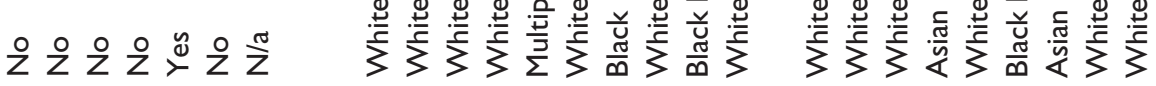

응 용 용 웅

\%ं

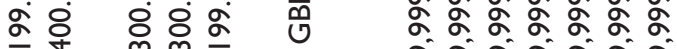

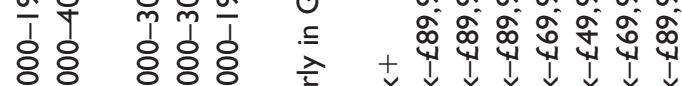

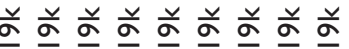

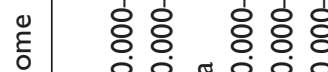

$\bar{\psi} \bar{w} \bar{w} \bar{w} \bar{w} \bar{w} \bar{w}$ 운 옥옥오옥옥음

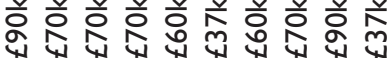

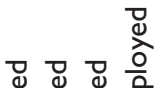

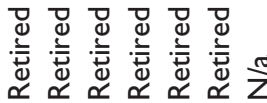

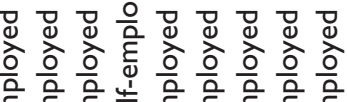

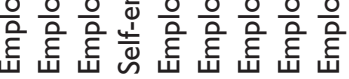

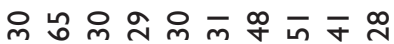

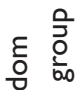

在一个m+L

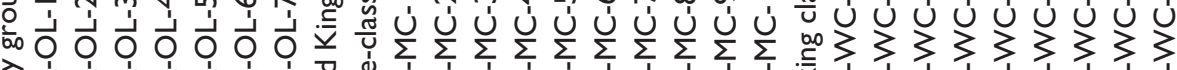

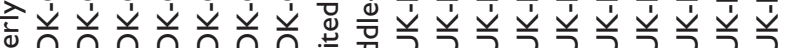
$\frac{0}{4}$ 


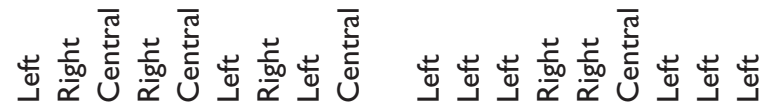

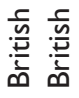

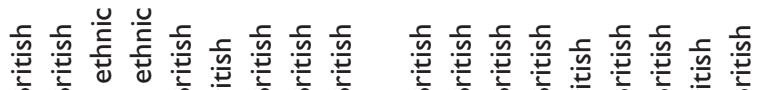
क के

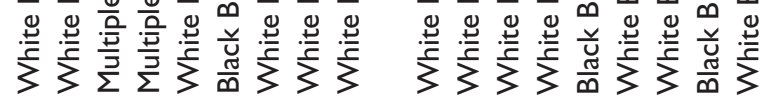

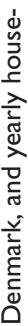

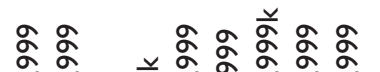

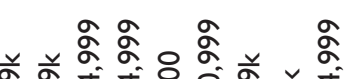

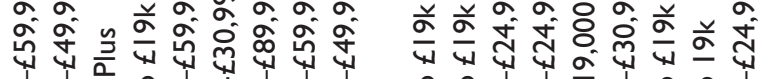

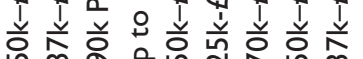

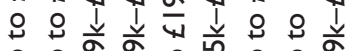

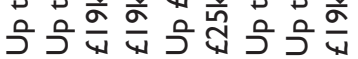

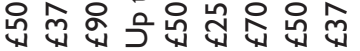

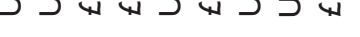

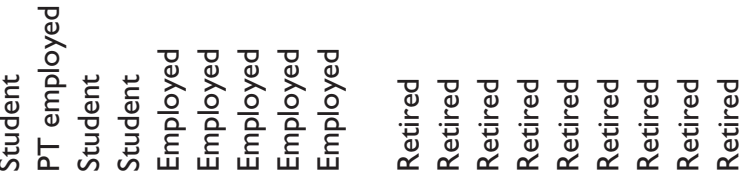

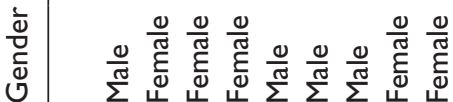

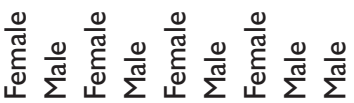

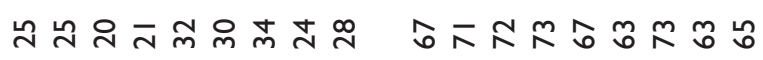




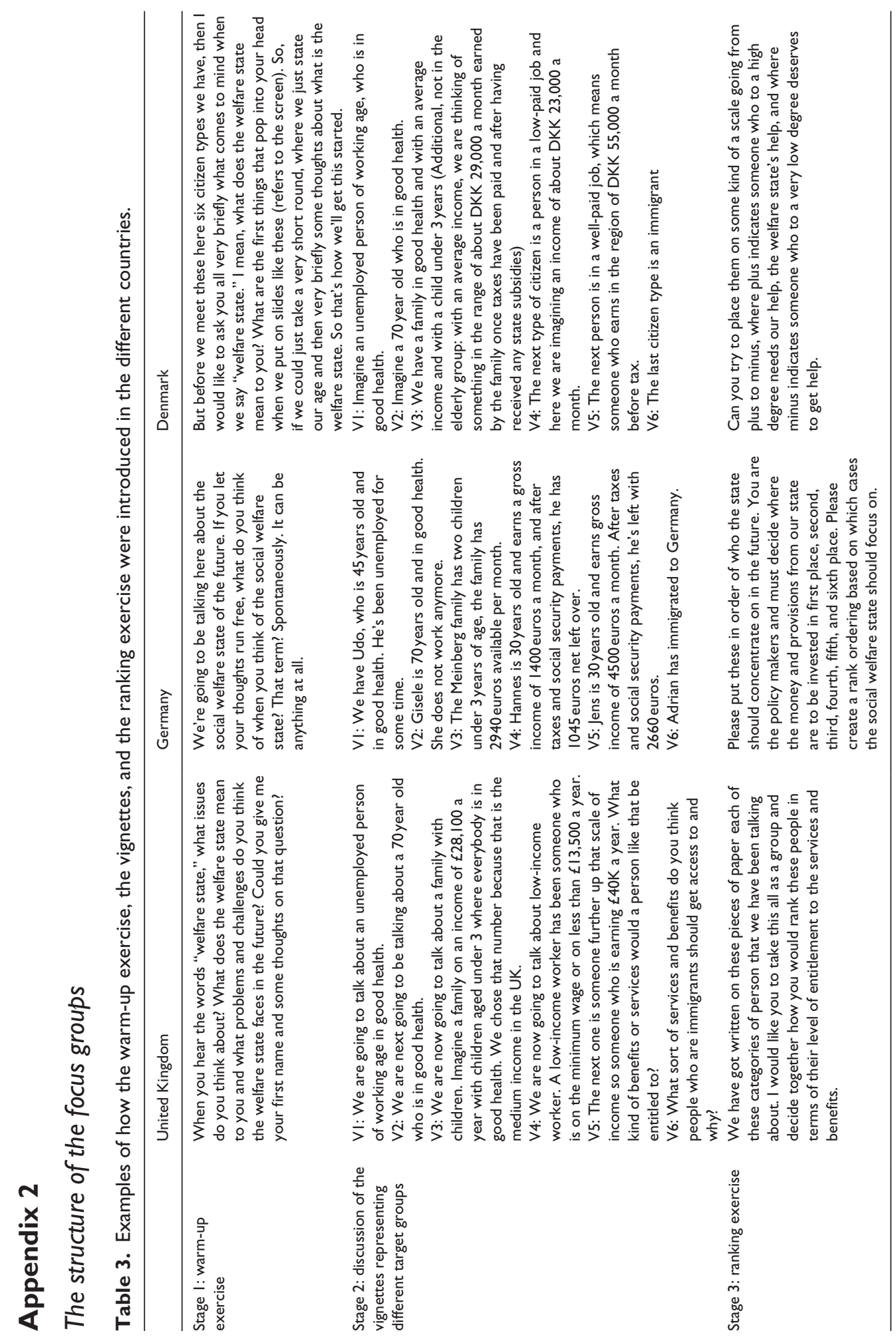




\section{Appendix 3}

\section{The final group rankings of the focus groups}

Table 4. Summary table of the final ranking for each group across countries.

\begin{tabular}{|c|c|c|c|c|c|c|}
\hline & Position I & Position 2 & Position 3 & Position 4 & Position 5 & Position 6 \\
\hline \multicolumn{7}{|l|}{ United Kingdom } \\
\hline Middle class & No ranking & & & & & \\
\hline Working class & Elderly and family & & Low-income & Immigrant & Well-off & Unemployed \\
\hline Young & Unemployed & Low-income & Family & Immigrant & Elderly & Well-off \\
\hline Elderly & Low-income & Unemployed & Family & Elderly & $\begin{array}{l}\text { Well-off and } \\
\text { immigrant }\end{array}$ & \\
\hline \multicolumn{7}{|l|}{ Germany } \\
\hline Middle class & Elderly & Low-income & Family & Unemployed & Well-off & Immigrant \\
\hline Working class & Family & Elderly & Low-income & Unemployed & Well-off & Immigrant \\
\hline Young & Family & Low-income & Unemployed & Elderly & Immigrant & Well-off \\
\hline Elderly & Family & Low-income & Unemployed & Elderly & Well-off & Immigrant \\
\hline \multicolumn{7}{|l|}{ Denmark } \\
\hline Middle class & Unemployed & Family & Immigrant & Low-income & Elderly & Well-off \\
\hline Working class & Elderly & Low-income & Well-off & Family & Unemployed & Immigrant \\
\hline
\end{tabular}

The UK middle-class group did not reach an agreement concerning the ranking. For Germany, we calculated the mean of each vignette's ranking position across participants in each group. 